\title{
Pretreatment Effect on CO Oxidation over Highly Ordered Mesoporous Silver Catalyst
}

\author{
Jeong Kuk Shon, Jung-Nam Park, ${ }^{*}$ Seong Hee Hwang, Mingshi Jin, Kiyoung Moon, \\ Jin-Hyo Boo, Tae Hee Han, ${ }^{\dagger}$ and Ji Man Kim*
}

\author{
Department of Chemistry, BK21 School of Chemical Materials Science, Department of Energy Science and SKKU Advanced \\ Institute of Nanotechnology, Sungkyunkwan University, Suwon 440-746, Korea \\ *E-mail: pjungnam@gmail.com (J.N.P); jimankim@skku.edu (J.M.K) \\ ${ }^{\dagger}$ Department of Semiconductor System, School of Information and Communication Engineering, \\ Sungkyunkwan University, Suwon 440-746, Korea \\ Received November 16, 2009, Accepted December 31, 2009
}

\begin{abstract}
Highly ordered mesoporous silver material was successfully synthesized from a mesoporous silica template (KIT-6) with 3-D channel structure using the nano-replication method. The effects of $\mathrm{H}_{2}$ or $\mathrm{O}_{2}$ pretreatments on the catalytic performance of the mesoporous silver were investigated using a temperature programmed $\mathrm{CO}$ oxidation technique in a fixed bed reactor. The mesoporous silver material that was pretreated with $\mathrm{H}_{2}$ exhibited an excellent catalytic activity compared to the as-prepared and $\mathrm{O}_{2}$-pretreated catalysts. Moreover, this present mesoporous silver material showed good catalytic stability. For the $\mathrm{CO}$ oxidation, the apparent activation energy of the $\mathrm{H}_{2}$-pretreated mesoporous silver catalyst was $61 \pm 0.5 \mathrm{~kJ} \mathrm{~mol}^{-1}$, which was also much lower than the as-prepared $\left(132 \pm 1.5 \mathrm{~kJ} \mathrm{~mol}^{-1}\right)$ and $\mathrm{O}_{2}$-pretreated $(124 \pm 1.4 \mathrm{~kJ}$ $\mathrm{mol}^{-1}$ ) catalysts.
\end{abstract}

Key Words: Nanostructure material, Mesoporous silver, Heterogeneous catalyst, CO oxidation, Pretreatment effect

\section{Introduction}

During the past few decades, considerable efforts have been devoted to the synthesis, modification and application of mesoporous materials because of their desirable physic-chemical properties such as high surface areas, well-ordered mesopores with regular pore sizes, and diverse framework compositions. After reports had been investigated on the synthesis of silica-based mesoporous materials, the research direction in these fields turned to the non-siliceous materials such as carbons, polymers, metal oxides, and metals. ${ }^{1}$ Even though some non-siliceous mesoporous materials have successfully been produced using surfactants or polymers as the templates, the preparation of these mesoporous materials is still challenging. Recently, a nano-replication route, where mesoporous silica or carbon materials are utilized as a rigid template, is regarded as a promising method for producing nano-siliceous mesoporous materials. ${ }^{2}$

The catalytic oxidation of carbon monoxide $(\mathrm{CO})$ is an important process in many applications such as air purification, pollution control devices, CO removal in heavy industry and vehicle exhaust, and fuel cells etc. ${ }^{3}$ In general, various types of metallic active species, such as $\mathrm{Pd},{ }^{4,5} \mathrm{Pt},{ }^{6,7} \mathrm{Rh},{ }^{8} \mathrm{Au},{ }^{9,10} \mathrm{Cu},{ }^{11}$ and $\mathrm{Co},{ }^{12}$ have been used for $\mathrm{CO}$ oxidation on the supports including $\mathrm{TiO}_{2}$, $\mathrm{Al}_{2} \mathrm{O}_{3}, \mathrm{SiO}_{2}, \mathrm{CeO}_{2}$ and zeolite catalysts. Recently, a report showed that transition metal oxides such as $\mathrm{Co}_{3} \mathrm{O}_{4}{ }^{13}$ and $\mathrm{CuO}-\mathrm{Fe}_{2} \mathrm{O}_{3}$ composites with mesoporous structures ${ }^{14}$ are active for $\mathrm{CO}$ oxidation at low temperatures. Tüysüz et al. reported that $\mathrm{Co}_{3} \mathrm{O}_{4}$ samples with high surface areas, were synthesized at different aging temperatures $\left(40,100\right.$ and $\left.135^{\circ} \mathrm{C}\right)$ and exhibited $100 \% \mathrm{CO}$ conversion to $\mathrm{CO}_{2}$ at low temperatures. ${ }^{13} \mathrm{Cao}$ et al. also reported that the mesoporous $\mathrm{CuO}-\mathrm{Fe}_{2} \mathrm{O}_{3}$ composites with different $\mathrm{CuO}$ concentrations were synthesized using the surfactant-assisted method of nanoparticle assembly and exhibited excellent activity and stability with $100 \% \mathrm{CO}$ conversion at $110{ }^{\circ} \mathrm{C}$. Mesoporous $\mathrm{RuO}_{2}$, which is replicated using cubic mesoporous silica, exhibits excellent activity with $100 \% \mathrm{CO}$ conversion at $165^{\circ} \mathrm{C},{ }^{15}$ whereas mesoporous $\alpha-\mathrm{Fe}_{2} \mathrm{O}_{3}$ had $100 \% \mathrm{CO}$ conversion at $280{ }^{\circ} \mathrm{C} .{ }^{14}$

Recently, highly ordered mesoporous silver material was synthesized using the nano-replication method with a cubic mesoporous silica template (KIT-6), and the surface hydrophobicity was controlled. ${ }^{16}$ Silver has attracted considerable attention because it can be applied in heterogeneous catalysis as well as advanced materials in the fields of antimicrobials and biosensors. ${ }^{17,18}$ Silver catalysts are also well-known for the epoxidation of ethylene. ${ }^{19}$ In this work, the catalytic properties of a mesoporous silver material were investigated for $\mathrm{CO}$ oxidation for the first time, and the pretreatment effects on the catalytic activity were addressed.

\section{Experimental}

Preparation of mesoporous silver samples. The mesoporous silica template, KIT-6, was synthesized following a method reported elsewhere. ${ }^{20}$ A triblock copolymer (Pluronic P123, $\mathrm{EO}_{20} \mathrm{PO}_{70} \mathrm{EO}_{20}$, Aldirch) and tetraethylorthosilicate (TEOS, Aldrich) were utilized as the structure-directing agent and the framework source, respectively. After calcination, the silica surface of KIT-6 was modified with methyl groups by refluxing a mixture containing $0.6 \mathrm{~g}$ hexamethyldisilazane (HMDS, 99\%, Fluka), $150 \mathrm{~mL}$ of $n$-hexane and $3.0 \mathrm{~g}$ of calcined KIT- 6 for $1 \mathrm{~h} .{ }^{16}$ To synthesize the mesoporous silver, a solution (containing $1.18 \mathrm{~g}$ of $\mathrm{AgNO}_{3}(99 \%$, Aldrich), $0.9 \mathrm{~g}$ of EtOH and $0.9 \mathrm{~g}$ of distilled water) was impregnated into $3.0 \mathrm{~g}$ of the modified KIT- 6 
template using an incipient wetness method. After drying at 80 ${ }^{\circ} \mathrm{C}$ for $24 \mathrm{~h}$, the composite was heated to $300{ }^{\circ} \mathrm{C}$ under a nitrogen flow for $24 \mathrm{~h}$. Subsequently, the silica template was completely removed by treating the composite material with a $3 \mathrm{M} \mathrm{NaOH}$ solution three times at $0{ }^{\circ} \mathrm{C}$. Finally, the mesoporous silver material was washed with distilled water and acetone several times and dried in a vacuum oven at room temperature for $12 \mathrm{~h}$. The asprepared mesoporous silver material was pretreated with $\mathrm{H}_{2}$ (or $\mathrm{O}_{2}$ ) at $300{ }^{\circ} \mathrm{C}$ for $2 \mathrm{~h}$ with a flowing gas mixture containing $10 \%$ $\mathrm{H}_{2}\left(\right.$ or $\left.\mathrm{O}_{2}\right)$ in Ar.

Material characterization and reaction measurements. The Xray diffraction patterns were obtained using the reflection mode of a Rigaku D/MAX-2200 ultima equipped with $\mathrm{Cu} \mathrm{K \alpha}$ at $30 \mathrm{kV}$ and $40 \mathrm{~mA}$. The scanning electron microscope (SEM) images were taken using LEO Supra 55 field emission scanning microscope that was operated at an accelerating voltage of $15 \mathrm{kV}$. The transmission electron microscope (TEM) images were obtained using a JEOL JEM 3010 at an accelerating voltage of $300 \mathrm{kV}$. The $\mathrm{N}_{2}$ adsorption-desorption isotherms were collected on a Micromeritics Tristar system at a liquid $\mathrm{N}_{2}$ temperature. $\mathrm{CO}$ was oxidized over the mesoporous silver catalyst at atmospheric pressure using a fixed bed reactor (inner diameter of $6 \mathrm{~mm}$ ) from a temperature range of 25 to $300{ }^{\circ} \mathrm{C}$, with a heating rate of $7.5^{\circ} \mathrm{C}$ $\min ^{-1}$. The feed gas $\left(4 \% \mathrm{CO}\right.$ in $\mathrm{O}_{2}$ and $\mathrm{Ar}$ ) was introduced through a packed bed of catalyst pellets (20 - 40 mesh) at an hourly space velocity (GHSV) of $16,700 \mathrm{~h}^{-1}$. The reaction gas mixture ratio of $\mathrm{CO} / \mathrm{O}_{2}$ was $1 / 5$. The final reaction product was analyzed using a mass spectrometer (Pfeiffer-vacuum, QMS 200 ), and the CO conversion was defined as the number of moles of $\mathrm{CO}_{2}$ produced after the reaction with respect to the amount of $\mathrm{CO}$ in feed gas.

\section{Results and Discussion}

Figure 1 shows the XRD patterns of the mesoporous silica template, KIT-6, and the mesoporous silver material obtained using the nano-replication method. KIT- 6 exhibited the typical XRD peaks (Figure 1a) of a 3-D cubic $(I a 3 d)$ mesostructure. ${ }^{16,20,21}$ However, in the XRD pattern for mesoporous silver, a new peak appeared in the low angle region of Figure $1 \mathrm{~b}$, which corresponded to the position of the [110] reflection for Ia3d symmetry. The presence of the [110] reflection indicated that the cubic Ia3 $d$ mesostructure was transformed into tetragonal $I 4_{1} / a$ (or lower) mesostructures after the silica template was removed. ${ }^{16}$ The wide-angle XRD pattern (inset of Figure 1b) contained several peaks at $2 \theta=38.1^{\circ}, 44.2^{\circ}, 64.4^{\circ}$ and $77.3^{\circ}$, which were characteristic of metallic silver.

The SEM and TEM images of the mesoporous silver material are provided in Figure 2. In Figure 2a, the mesoporous silver exhibited an irregular morphology, with sizes that were a few micrometers. The highly ordered mesostructures of the mesoporous silver were confirmed by the SEM (Figure 2b) and TEM (Figure 2c) images. In Figure 2d, the framework thickness of the mesoporous silver material was about $8 \mathrm{~nm}$, which was very similar to the average silver domain size (about $8.2 \mathrm{~nm}$ ) that was calculated from the XRD line-broadening using the Scherrer formula. This value was also similar to the pore size of the mesoporous silica template, KIT-6 $(7.2 \mathrm{~nm}$, Table 1).
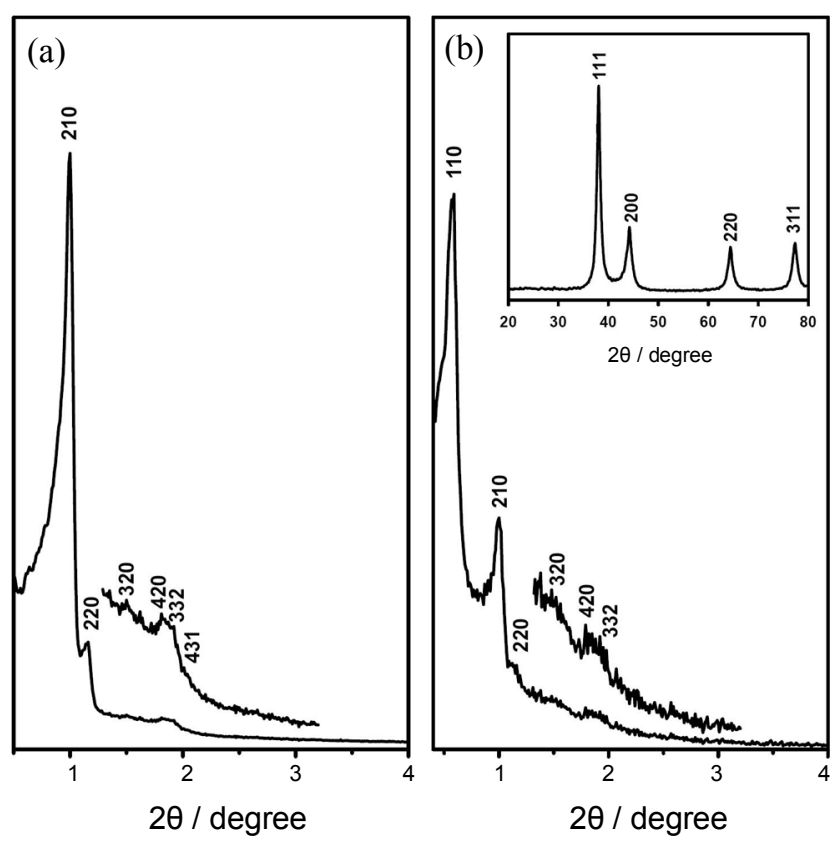

Figure 1. XRD patterns of (a) the silica template KIT-6 and (b) the mesoporous silver. The inset of (b) is a high-angle XRD pattern of the mesoporous silver.
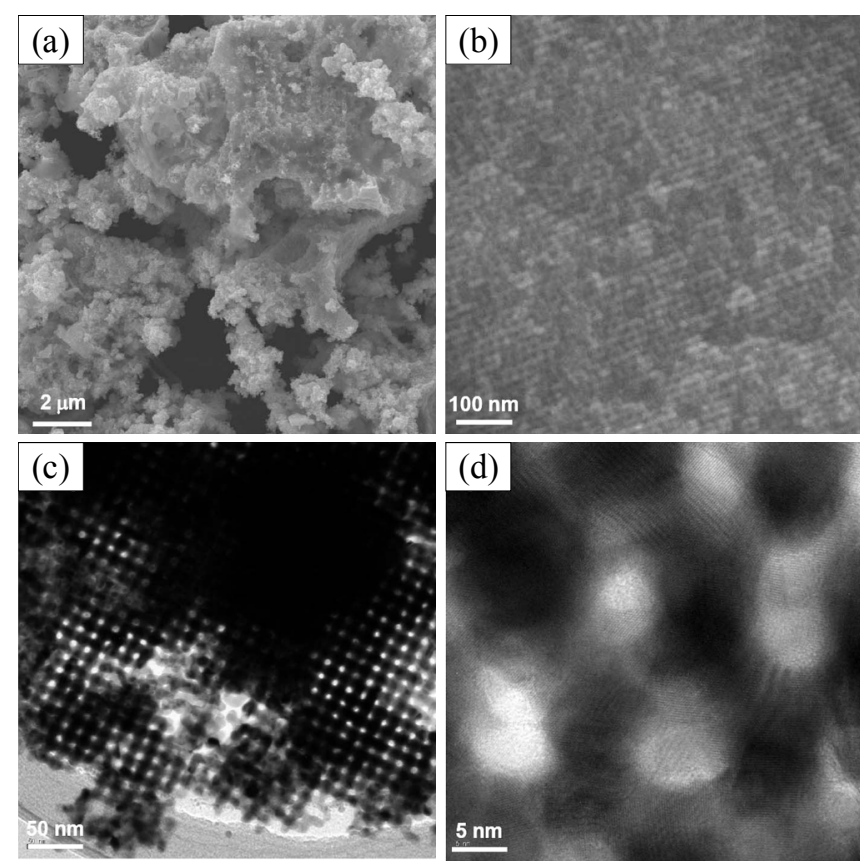

Figure 2. (a,b) SEM images and $(c, d)$ TEM images of the mesoporous silver material.

Figure 3 shows the $\mathrm{N}_{2}$ adsorption-desorption isotherms and the corresponding BJH pore size distribution curves for the mesoporous silica template, KIT-6, and the mesoporous silver material. In Figure 3, all of the $\mathrm{N}_{2}$ sorption isotherms were typical type-IV isotherms with hysteresis, indicating that the materials exhibited well-defined mesostructures. The physical properties of the mesoporous silica template and the corresponding mesoporous silver material are summarized in Table 1. The BET 
Table 1. Physical properties of the mesoporous silica template KIT-6 and the mesoporous silver materials.

\begin{tabular}{cccc}
\hline Material & $S_{\text {BET }}\left(\mathrm{m}^{2} / \mathrm{g}\right)^{a}$ & $D_{\text {pore }}(\mathrm{nm})^{b}$ & $V_{\text {tot }}(\mathrm{cc} / \mathrm{g})^{c}$ \\
\hline KIT-6 & 769 & 7.2 & 1.00 \\
Mesoporous Ag & 31 & 15.5 & 0.08 \\
\hline
\end{tabular}

${ }^{a}$ Surface areas calculated using the BET method. ${ }^{b}$ Mesopore diameters obtained from the $\mathrm{N}_{2}$ adsorption branches using the BJH method. ${ }^{c}$ Total pore volumes estimated from the $\mathrm{N}_{2}$ sorption isotherms at $p / p_{0}=0.99$.

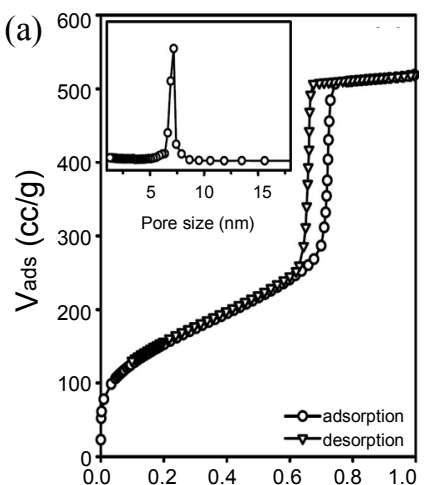

Relative pressure $\left(p / p_{0}\right)$

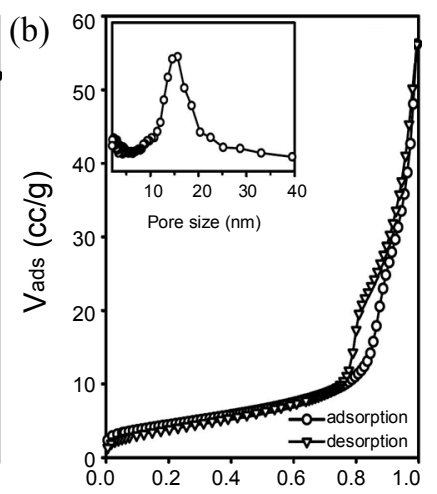

Relative pressure $\left(p / p_{0}\right)$
Figure 3. $\mathrm{N}_{2}$ adsorption-desorption isotherms of (a) the silica template KIT-6 and (b) the mesoporous silver material. The insets correspond to the $\mathrm{BJH}$ pore size distribution curves.

surface area of the mesoporous silver was $31 \mathrm{~m}^{2} \mathrm{~g}^{-1}$. The $\mathrm{N}_{2}$ isotherm of the mesoporous silver had a well-defined step in the adsorption-desorption curves around a relative pressure, $p / p_{0}$, of $0.8-0.9$, and the corresponding BJH pore size obtained from the adsorption branch was about $15.5 \mathrm{~nm}$, which was much larger than the wall thickness of the silica template probably because of the phase transformation from Ia $3 d$ to a $I 4_{1} / a$ (or lower) mesostructure for the mesoporous silver after the silica removal, as expected from the XRD patterns.

Figure 4 shows the dependence of the temperature programmed CO oxidation on the pretreatment conditions for the mesoporous silver materials, and the catalytic activities are listed in Table 2. Although the as-prepared mesoporous Ag exhibited the metallic phase in XRD pattern (Inset of Figure 1b), its surface might be partially oxidized. Therefore, the temperature programmed $\mathrm{CO}$ oxidation was performed without and with pretreatment using different atmospheres in order to investigate the effect of surface property on the catalytic activity. Without pretreatment, the $\mathrm{CO}$ oxidation started at $250^{\circ} \mathrm{C}$ and reached a $100 \%$ conversion at $260^{\circ} \mathrm{C}$. In Figure $4 \mathrm{a}$ and Table 2 , the $\mathrm{H}_{2}$ pretreatment before the $\mathrm{CO}$ oxidation drastically improved the catalytic activity of the mesoporous silver material. The light-off temperature was much lower $\left(T_{\text {start }}=65^{\circ} \mathrm{C}\right)$ than the as-prepared catalyst. The mesoporous silver material that was pretreated with $\mathrm{O}_{2}$ exhibited a similar (or lower) catalytic activity to untreated mesoporous silver catalyst. The inset of Figure 4 shows an Arrhenius plot for the mesoporous silver catalysts that was obtained from the $\mathrm{CO}$ oxidation data, and the corresponding apparent activation energies $\left(E_{\mathrm{a}}\right)$ of the mesoporous silver cata-

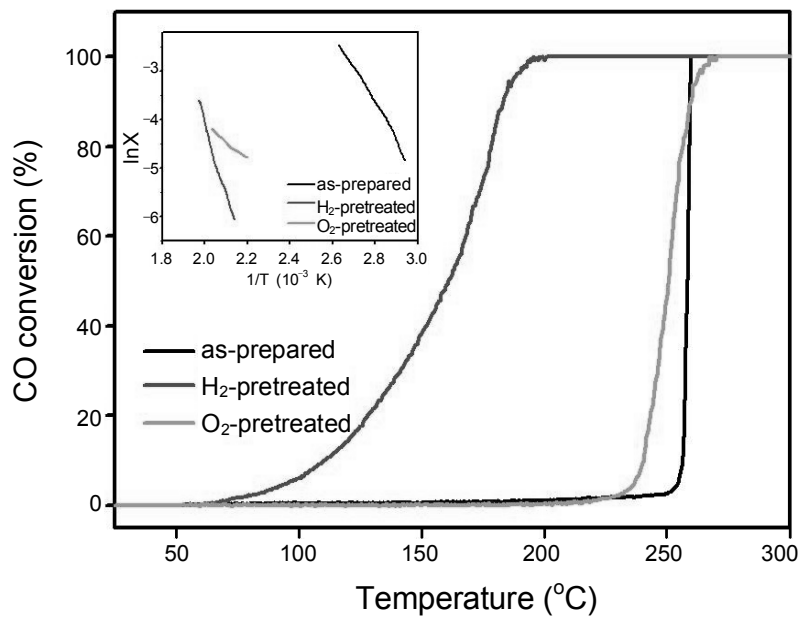

Figure 4. Temperature-programmed $\mathrm{CO}$ oxidation dependence on the pretreatment conditions for the mesoporous silver material. The inset is an Arrhenius plot of $\mathrm{CO}$ conversion.

Table 2. Light-off temperature and activation energy of the CO oxidation for the mesoporous silver catalyst.

\begin{tabular}{crrrr}
\hline \multirow{2}{*}{ Pretreatment } & \multicolumn{3}{c}{ Light-off temperature $\left({ }^{\circ} \mathrm{C}\right)$} & \multirow{2}{*}{$E_{\mathrm{a}}\left(\mathrm{kJ} \mathrm{mol}^{-1}\right)^{d}$} \\
\cline { 2 - 4 } & \multicolumn{1}{c}{$T_{\text {start }}{ }^{a}$} & $T_{50}{ }^{b}$ & $T_{100}{ }^{c}$ & \\
\hline as-prepared & 250 & 258 & 260 & $132 \pm 1.5$ \\
$\mathrm{H}_{2}$ treatment & 65 & 161 & 195 & $61 \pm 0.5$ \\
$\mathrm{O}_{2}$ treatment & 225 & 251 & 267 & $124 \pm 1.4$ \\
\hline
\end{tabular}

${ }^{a}$ Temperatures when $\mathrm{CO}$ conversion starts. ${ }^{b}$ Temperatures when $\mathrm{CO}$ conversion reaches to $50 \%$. ${ }^{c}$ Temperatures at $\mathrm{CO}$ conversion of $100 \%$. ${ }^{d} \mathrm{Appa}-$ rent activation energy calculated from Arrhenius plots.

lysts with various pretreatment conditions are listed in Table 2 for the $\mathrm{CO}$ oxidation. The activation energy of the $\mathrm{H}_{2}$-pretreated mesoporous silver $\left(61 \pm 0.5 \mathrm{~kJ} \mathrm{~mol}^{-1}\right)$ was much lower than the as-prepared and $\mathrm{O}_{2}$-pretreated catalysts $\left(132 \pm 1.5 \mathrm{~kJ} \mathrm{~mol}^{-1}\right.$ and $124 \pm 1.4 \mathrm{~kJ} \mathrm{~mol}^{-1}$, respectively) and slightly lower than the $E_{\mathrm{a}}$ of an $\mathrm{Ag} / \mathrm{CeO}_{2}$ catalyst $\left(71 \mathrm{~kJ} \mathrm{~mol}^{-1}\right){ }^{22}$ Unlike Pt surfaces that facilitate $\mathrm{CO}$ to $\mathrm{CO}_{2}$ through dissociative chemisorptions of oxygen and the molecular adsorption of $\mathrm{CO}$, dissociative chemisorptions of oxygen and $\mathrm{CO}$ coverage do not easily occur on $\mathrm{Ag}$ metal surfaces. ${ }^{23,24}$ Bera et al. reported that the catalytic activity of $1 \mathrm{wt} \% \mathrm{Ag} / \mathrm{CeO}_{2}\left(T_{100}=260^{\circ} \mathrm{C}\right)$ was higher than $1 \mathrm{wt} \% \mathrm{Ag} /$ $\mathrm{Al}_{2} \mathrm{O}_{3}\left(T_{100}=350{ }^{\circ} \mathrm{C}\right)$ for $\mathrm{CO}$ oxidation. ${ }^{22}$ In this present study, similar results were observed for as-prepared mesoporous silver catalyst without any treatment, which exhibited a $100 \% \mathrm{CO}$ conversion at $260^{\circ} \mathrm{C}$. However, the $\mathrm{CO}$ oxidation for the mesoporous silver material that was pretreated with $\mathrm{H}_{2}$ began at a relati vely lower temperature and was complete at a temperature of $195^{\circ} \mathrm{C}$. According to these catalytic results, the surface species of the mesoporous silver material seems to be very important to the $\mathrm{CO}$ oxidation. Although all of the mesoporous silver materials exhibited metallic phases (Figure 5), the mesoporous silver material that was pretreated with $\mathrm{H}_{2}$ might have sufficient defects for the dissociative chemisorptions of oxygen, and hence, an improved catalytic activity for the low temperature $\mathrm{CO}$ oxidation was shown, unlike the as-prepared and $\mathrm{O}_{2}$-pretreated meso- 


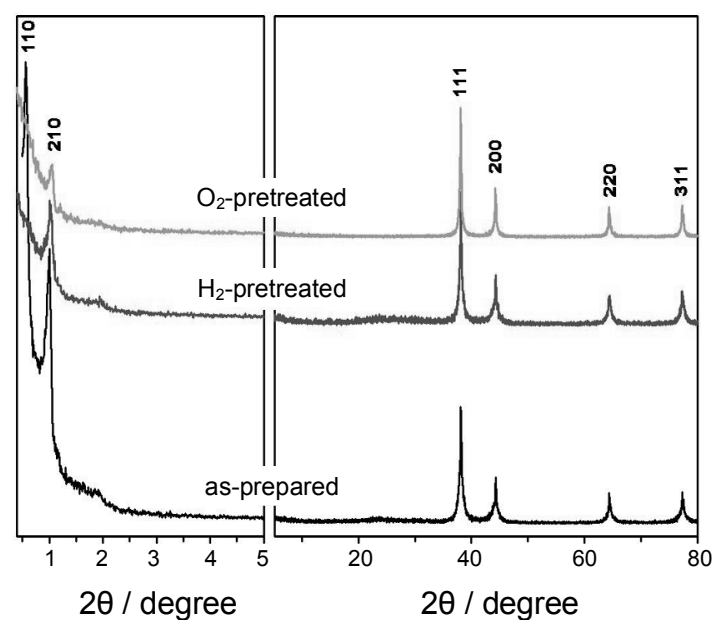

Figure 5. XRD patterns of the mesoporous silver materials before and after the pretreatments.

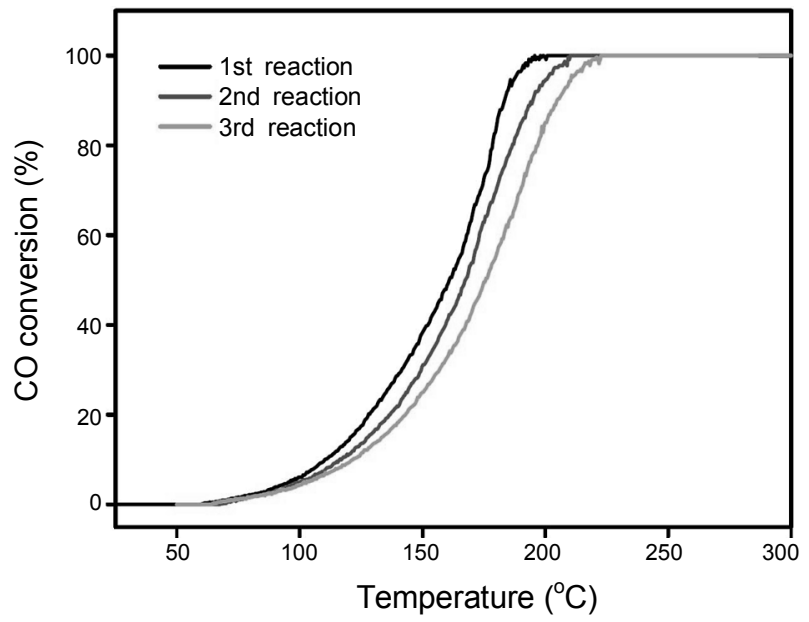

Figure 6. Catalytic stability of the mesoporous silver material that was pretreated $\mathrm{H}_{2}$ for the $\mathrm{CO}$ oxidation.

porous silver materials, which were less active for the CO oxidation.

Figure 6 illustrates the catalyst stability of the $\mathrm{CO}$ oxidation for the mesoporous silver material that was pretreated with $\mathrm{H}_{2}$. Each CO oxidation was carried out from 25 to $300{ }^{\circ} \mathrm{C}$. Even though the catalytic activity slightly decreased upon repeated CO oxidations, a significant deactivation was not observed in Figure 6.

\section{Conclusions}

A highly ordered mesoporous silver material was synthesized using the nano-replication method from a mesoporous silica template, KIT-6, with 3D cubic mesostructure (Ia3d), and the dependence of the $\mathrm{CO}$ oxidation on the pretreatment conditions was investigated for the material. The as-prepared and $\mathrm{O}_{2}$-pre- treated mesoporous silver catalysts exhibited similar catalytic performances, showing a $100 \% \mathrm{CO}$ conversion at $260 \sim 267^{\circ} \mathrm{C}$. However, the catalytic activity was dramatically improved by $\mathrm{H}_{2}$ pretreatment, and the light-off temperature $\left(T_{\text {start }}=65^{\circ} \mathrm{C}\right)$ and activation energy $\left(61 \pm 0.5 \mathrm{~kJ} \mathrm{~mol}^{-1}\right)$ were much lower than the as-prepared and $\mathrm{O}_{2}$-pretreated mesoporous silver catalysts $\left(T_{\text {start }}=250{ }^{\circ} \mathrm{C} ; 132 \pm 1.5 \mathrm{~kJ} \mathrm{~mol}^{-1}\right.$, and $T_{\text {start }}=225^{\circ} \mathrm{C} ; 124 \pm 1.4$ $\mathrm{kJ} \mathrm{mol}^{-1}$, respectively). The mesoporous silver material that was pretreated with $\mathrm{H}_{2}$ also exhibited excellent catalyst stability, even though the catalytic activity and mesostructure slightly decreased upon repeating the $\mathrm{CO}$ oxidation cycle.

Acknowledgments. This work was supported by the Priority Research Centers Program (project No. 20090094025) and Basic Science Research Program (2009-0076903) through the National Research Foundation of Korea (NRF). J. M. Kim would also like to thank the WCU (World Class University, R31-2008000-10029-0).

\section{References}

1. Yang, H. F.; Zhao, D. Y. J. Mater. Chem. 2005, 15, 1217.

2. Schüth, F. Chem. Mater. 2001, 13, 3184.

3. Centi, G.; Ciambelli, P.; Perathoner, S.; Russo, P. Catal. Today 2002, 75, 3 .

4. Park, J. N.; Forman, A. J.; Tang, W.; Cheng, J. H.; Hu, Y. S.; Lin, H. F.; McFarland, E. W. Small 2008, 4, 1694.

5. Oh, S. H.; Hoflund, G. B. J. Phys. Chem. A 2006, 110, 7609.

6. Li, S.; Liu, G.; Lian, H.; Jia, M.; Zhao, G.; Jiang, D.; Zhang, W. Catal. Commun. 2008, 9, 1045.

7. Yang, J.; Tschamber, V.; Habermacher, D.; Garin, F.; Gilot, P. Appl. Catal. B: Environ. 2008, 83, 229.

8. Flege, J. I.; Sutter, P. Phys. Rev. B 2008, 78, 153402.

9. Peng, S.; Lee, Y.; Wang, C.; Yin, H.; Dai, S.; Sun, S. Nano Research 2008, 1, 229.

10. Wu, Z. L.; Zhou, S. H.; Zhu, H. G.; Dai, S.; Overbury, S. H. Chem. Commun. 2008, 3308

11. Chen, C.-S.; You, J.-H.; Lin, J.-H.; Chen, Y.-Y. Catal. Commun. 2008, 9, 2381-2385.

12. Jansson, J.; Skoglundh, M.; Fridell, E.; Thormählen, P. Top. Catal. 2001, 16-17, 385.

13. Tuysuz, H.; Comotti, M.; Schuth, F. Chem. Commun. 2008, 4022.

14. Cao, J. L.; Wang, Y.; Yu, X. L.; Wang, S. R.; Wu, S. H.; Yuan, Z. Y. Appl. Catal. B-Environ. 2008, 79, 26.

15. Shen, W.; Shi, J.; Chen, H.; Gu, J.; Zhu, Y.; Dong, X. Chem. Lett. $\mathbf{2 0 0 5}, 34,390$.

16. Shon, J. K.; Kong, S. S.; Kim, J. M.; Ko, C. H.; Jin, M.; Lee, Y. Y.; Hwang, S. H.; Yoona, J. A.; Kim, J. N. Chem. Commun. 2009, 650.

17. Tao, A.; Kim, F.; Hess, C.; Goldberger, J.; He, R.; Sun, Y.; Xia, Y.; Yang, P. Nano lett. 2003, 3, 1229.

18. Jana, N. R.; Sau, T. K.; Pal, T. J. Phys. Chem. 1999, 103, 115.

19. de Carvalho, M.; Passos, F. B.; Schmal, M. J. Catal. 2007, 248 , 124.

20. Kleitz, F.; Choi, S. H.; Ryoo, R. Chem. Commun. 2003, 2136.

21. Shon, J. K.; Kong, S. S.; Kim, Y. S.; Lee, J. H.; Park, W. K.; Park, S. C.; Kim, J. M. Microp. Mesop. Mat. 2009, 120, 441.

22. Bera, P.; Patil, K. C.; Hegde, M. S. Phys. Chem. Chem. Phys. 2000, 2,3715

23. Engel, T.; Ertl, G. Advan. Catal. 1979, $28,1$.

24. Burghaus, U.; Conrad, H. Surf. Science 1995, 331, 116. 